\section{Do all daily metabolic equivalent task units (METs) bring the same health benefits?}

\author{
Andreas Holtermann, ${ }^{1,2}$ Emmanuel Stamatakis ${ }^{\circledR, 4}$
}

In physical activity (PA) and exercise science, the prevailing view is that the health effect of PA is mainly determined by the accumulated rate of energy spent on PA over the day. Accordingly, generations of PA guidelines are based on the rate of energy spent during different tasks of PA, termed 'metabolic equivalent tasks' (abbreviated to 'METs') (see table 1). Accumulated daily METs (expressed in, for example, MET-hours or MET-minutes) are probably the most common in health-related measure of PA. But do daily METs really 'tell the whole story' of the health effects from PA?

The report of the 2018 US Physical Activity Guidelines Advisory Committee ${ }^{1}$ represents the most up-to-date guidance on physical activity and health. Despite multiple novel elements, these guidelines encompass (eg, influence of PA on sleep and fatigue) the thinking that all METs are the same, no matter the context they are accrued in, still remains. But the evidence behind 'the more daily METs-the better' is generally limited to specific domains and intensities of PA. Some of the most authoritative information on dose-response of PA and mortality risk is limited to recreational moderate-intensity to vigorous-intensity PA (MVPA). ${ }^{2}$ However, in high-income, middle-income and low-income countries alike, the majority of daily METs is spent in non-recreational settings (occupation, transportation, housework), and low-income countries spend less time in MVPA than high-income countries. ${ }^{3}$

PA at work is shown to not provide the same health gain as recreational $\mathrm{PA},{ }^{4}$ and the health effects of light-intensity PA, where most METs are spent, are largely

\footnotetext{
${ }^{1}$ National Research Centre for the Working Environment (NRCWE), Copenhagen, Denmark

${ }^{2}$ Department of Sports Science and Clinical

Biomechanics, University of Southern Denmark, Odense, Denmark

${ }^{3}$ Epidemiology Unit, Charles Perkins Centre, University of Sydney, Sydney, New South Wales, Australia

${ }^{4}$ Prevention Research Collaboration, School of Public Health, Faculty of Medicine and Health, University of Sydney, Sydney, New South Wales, Australia
}

Correspondence to Dr Andreas Holtermann, National Research Centre for the Working Environment, Copenhagen, 2100, Denmark; aho@nrcwe.dk unknown. This suggests that the health effects of PA do not depend merely on total duration and the loading of the cardiorespiratory and muscular systems, which primarily determines the daily METs.

A number of crucial PA attributes beyond daily METs for health are either unexplored or have received very little attention, for example:

1. Improvements in cardiorespiratory fitness (CRF) requires PA of relatively high intensity ( $>60 \%$ of maximal CRF). Thus, large volumes of daily METs at a lower intensity may improve metabolic fitness, but not CRF (due to insufficient stimulus on the cardiorespiratory system to adapt for higher PA demands). Workers in manual jobs (eg, cleaners) measured to walk about 20000 steps per day still have poor $\mathrm{CRF}^{5}$ On the contrary, high-intensity interval training for very short time improves CRF despite low total METs spent.

2. Office workers are recommended to sit less and stand more. Substituting sitting with standing over several working hours may increase daily METs to some extent. However, in an occupational setting, high durations of stationary standing at work (eg, in manufacturing production lines, hair dressers and service sector) are also documented to increase the risk for musculoskeletal ${ }^{6}$ and circulatory ${ }^{7}$ problems.

3. The PA time pattern is important for its health effects. Prolonged bouts of lack of movement are associated with all-cause mortality risk independent of daily METs.

4. Types of sports and exercise requiring dynamic use of large muscle mass (eg, swimming and racquet sports) are associated with lower all-cause and cardiovascular disease mortality risk compared with sports of similar METs that do not occupy the entire body. ${ }^{9}$

These lines of evidence suggest that promotion of more PA during recreation, work, transportation or domestic life will not give the same return of investment in health.

In the last four to five decades, we caught merely a glimpse of the huge potential of PA for health benefits. Although self-reported PA time and MET measuring methodologies have produced an extremely important evidence base, they have important limitations, such as inability to capture incidental PA of light intensity and posture, differential measurement error by PA domain, and relatively poor validity and accuracy. Today's measuring technologies are both feasible and accurate enough for large-scale collection and detailed characterisation of the health attributes of many aspects of PA that are virtually unexplored. ${ }^{10}$ In the not-so-distant future, such technologies could revolutionise what we know about PA and health by tightly integrating METs with different PA dimensions, such as postures and types of PA. This technology combined with modern collaboration platforms like consortia, global networks and prospective meta-analysis platforms offers tremendous potential for making our discipline-PA, Exercise and Health-a model health-related scientific field. But
Table 1 Examples of types of physical activities resulting in different categories of metabolic equivalent tasks (METs)

\begin{tabular}{|c|c|c|c|c|}
\hline MET categories & $\leq 1.0$ to $\leq 1.5$ & $<1.5$ to $<3.0$ & $\leq 3.0$ to $<6$ & $\leq 6$ \\
\hline $\begin{array}{l}\text { Physical activity } \\
\text { categories }\end{array}$ & Sedentary+standing & $\begin{array}{l}\text { Light-intensity } \\
\text { physical activity }\end{array}$ & $\begin{array}{l}\text { Moderate-intensity } \\
\text { physical activity }\end{array}$ & $\begin{array}{l}\text { Vigorous physical } \\
\text { activity }\end{array}$ \\
\hline \multirow[t]{2}{*}{$\begin{array}{l}\text { Examples of physical } \\
\text { activities }\end{array}$} & $\begin{array}{l}\text { Lying, sitting and } \\
\text { stationary standing }\end{array}$ & $\begin{array}{l}\text { Slow walking } \\
(<4 \mathrm{~km} / \mathrm{h})\end{array}$ & $\begin{array}{l}\text { Moderate and fast } \\
\text { walking }(4-7 \mathrm{~km} / \mathrm{h})\end{array}$ & $\begin{array}{l}\text { Very fast walking } \\
(>7 \mathrm{~km} / \mathrm{h})\end{array}$ \\
\hline & $\begin{array}{l}\text { Sitting quietly (eg, } \\
\text { watching television } \\
\text { and car driving) and } \\
\text { standing (eg, during } \\
\text { computer work) }\end{array}$ & $\begin{array}{l}\text { Sitting tasks with } \\
\text { moderate effort (eg, } \\
\text { operating heavy } \\
\text { machinery) and } \\
\text { standing with minor } \\
\text { effort (eg, active } \\
\text { workstation) }\end{array}$ & $\begin{array}{l}\text { Bicycling or walking } \\
\text { for transportation } \\
\text { and most manual } \\
\text { labour (eg, garbage } \\
\text { collecting, carpentry, } \\
\text { bricklaying or } \\
\text { masonry) }\end{array}$ & $\begin{array}{l}\text { Running, swimming, } \\
\text { bicycling for exercise, } \\
\text { carrying heavy loads } \\
\text { or moderate loads up } \\
\text { a flight of stairs }\end{array}$ \\
\hline
\end{tabular}

This one-dimensional MET-based categorisation has been the general framework for the physical activity recommendations. 
little value will be realised without better collaboration and tighter communication between researchers of all PA subdisciplines, including public health, occupational health, epidemiology, computer science, statistics and engineering.

Acknowledging the possibility that not all daily METs are the same in our scientific inquiry is an important step towards realising the full potential of bodily movement for promoting health.

Contributors Both authors contributed to conception of the research idea as well as drafting and finalising the manuscript.

Funding The authors have not declared a specific grant for this research from any funding agency in the public, commercial or not-for-profit sectors.

Competing interests None declared.

Patient consent Not required.

Provenance and peer review Not commissioned; externally peer reviewed.

\section{(1) OPEN ACCESS}

Open access This is an open access article distributed in accordance with the Creative Commons Attribution
Non Commercial (CC BY-NC 4.0) license, which permits others to distribute, remix, adapt, build upon this work non-commercially, and license their derivative works on different terms, provided the original work is properly cited and the use is non-commercial. See: http:// creativecommons.org/licenses/by-nc/4.0/

(C) Article author(s) (or their employer(s) unless otherwise stated in the text of the article) 2019. All rights reserved. No commercial use is permitted unless otherwise expressly granted.

\section{D) Check for updates}

To cite Holtermann A, Stamatakis E. Br J Sports Med 2019;53:991-992.

Accepted 2 May 2018

Published Online First 24 May 2018

Br J Sports Med 2019:53:991-992.

doi:10.1136/bjsports-2017-098693

\section{REFERENCES}

1 Physical activity guidelines advisory commitee. Physical activity guidelines advisory commitee scientific report 2018. Washington, DC, USA: Department of Health and Human Services, 2018.

2 Arem H, Moore SC, Patel A, et al. Leisure time physical activity and mortality: a detailed pooled analysis of the dose-response relationship. JAMA Intern Med 2015; 175:959-67.

3 Lear SA, Hu W, Rangarajan S, et al. The effect of physical activity on mortality and cardiovascular disease in 130000 people from 17 high-income, middle-income, and low-income countries: the PURE study. The Lancet 2017;390:2643-54.

4 Holtermann A, Krause N, van der Beek AJ, et al. The physical activity paradox: six reasons why occupational physical activity (OPA) does not confer the cardiovascular health benefits that leisure time physical activity does. $\mathrm{Br}$ I Sports $\mathrm{Med}$ 2018; 52 .

5 Korshøj M, Krustrup P, Jespersen T, et al. A 24-h assessment of physical activity and cardio-respiratory fitness among female hospital cleaners: a pilot study. Ergonomics 2013;56:935-43.

6 Coenen P, Parry S, Willenberg L, et al. Associations of prolonged standing with musculoskeletal symptoms-a systematic review of laboratory studies. Gait Posture 2017;58:310-8.

7 Waters TR, Dick RB. Evidence of health risks associated with prolonged standing at work and intervention effectiveness. Rehabil Nurs 2015;40:148-65.

8 Diaz KM, Howard VJ, Hutto B, et al. Patterns of sedentary behavior and mortality in U.S. middle-aged and older adults: a national cohort study. Ann Intern Med 2017;167:465-75.

9 Oja P, Kelly P, Pedisic Z, et al. Associations of specific types of sports and exercise with all-cause and cardiovascular-disease mortality: a cohort study of 80306 British adults. Br I Sports Med 2017;51:812-7.

10 Schneller MB, Pedersen MT, Gupta N, et al. Validation of five minimally obstructive methods to estimate physical activity energy expenditure in young adults in semi-standardized settings. Sensors 2015;15:6133-51. 